Pharmacokinetics

\section{Isoniazid treatment of children: can genetics help guide treatment?}

\section{N Cranswick, K Mulholland}

\section{Commentary on the paper by Schaaf et al (see page 614)}

$\mathrm{H}$ alf of the world's population are children, yet many of the most important developments in drug therapy ignore the needs of this most vulnerable population. With Mycobacterium tuberculosis as the cause of one of the most important chronic infectious diseases worldwide, ${ }^{1}$ it is gratifying to see research that describes the integration of modern molecular techniques to improve the delivery of the most important component of tuberculosis treatment for the world's children. The study by Schaaf and colleagues, ${ }^{2}$ reported in this issue of the journal, focuses our attention on isoniazid therapy which is still the mainstay of tuberculosis therapy for both adults and children.

For most drugs, children need specific doses, usually defined in terms of body weight. Extrapolation of the dose from adult studies by body weight would result in the under-dosing of many drugs, as children are proportionally more efficient at clearing the drugs. ${ }^{3}$ Isoniazid is a good example. The study by Schaaf et al highlights the fact that not only are higher doses required in childhood to achieve the same levels as adults, but also that children are as metabolically heterogeneous as adults. Correct dosage is important to maximise the chances of effective treatment, and to minimise the chances of adverse effects, both serious and minor. Adherence in tuberculosis treatment of children is poor ${ }^{4}$ and may be improved by minimising adverse effects of therapy.

Where a drug is being used for the treatment of infections, the appropriate efficacious dose is defined by the characteristics of the organism as well as host factors such as absorption. Drug exposure must be adequate to control or eliminate the infection. ${ }^{56}$ Adverse effects are host dependent and may be dose related or idiosyncratic. Many of the serious side effects associated with isoniazid, such as hepatotoxicity, although thought to be idiosyncratic, may be dependent to some extent on the dose chosen and the serum drug levels achieved..$^{78}$ Fortunately, serious side effects, such as dose related peripheral neuropathy are less common in children than adults. ${ }^{9}$ However, children who are severely malnourished may be at increased risk of side effects; especially those involving the nervous system. ${ }^{10}$ This is particularly important in the treatment of tuberculosis, as children with tuberculosis are often severely malnourished at the time they start treatment, as were almost half of the children in the Schaff et al study. In these cases, supplementation with pyridoxine rather than dose adjustment may be more important as this has been shown to reduce the risk of toxicity. ${ }^{10}$ Tolerability is dictated by dose related minor side effects such as nausea, vomiting, and anorexia. These may not require withdrawal of the drug but can influence adherence to a regimen, and could therefore influence efficacy.

The current approach to dosing children is procrustean (see box) with a one size fits all approach. WHO and the International Union Against Tuberculosis and Lung Disease (IUATLD) recommend, for all patients regardless of age, a dose of $5 \mathrm{mg} / \mathrm{kg} / \mathrm{day}$ where the drug is given daily and $10 \mathrm{mg} / \mathrm{kg} /$ day where the drug is given three times a week. Higher doses have been recommended in severe disease. ${ }^{11}$ The study of Schaaf et al presents a strong argument that dosage should be tailored based on age and possibly genotype. Pharmacogenetics has identified differences in drug clearance based on the genetic profile of the metabolising enzymes; this is most relevant for drugs that are primarily cleared by hepatic elimination. ${ }^{12}$ The CPY450 pathways have been the most extensively investigated and reported upon. However, for INH, it is phase II acetylation by $\mathrm{N}$-acetyltransferase 2 (NAT2) which is the rate limiting step in drug elimination. ${ }^{13}{ }^{14}$ The enzyme is subject to genetic polymorphism, which results in fast (FF), slow (SS), and intermediate (FS) metabolisers. Schaaf et al investigated a group of 64 children less than 13 years of age with a standard $10 \mathrm{mg} / \mathrm{kg}$ dose of isoniazid. They showed that, following a single dose of the drug, the slow metabolisers had concentrations at two hours approximately double those of the fast group and total drug exposures over three times those of the fast group. The intermediate group had a profile that was between the two, although the total exposure to the drug (as measured by the area under the drug concentration by time curve) was closer to the fast group. These differences were primarily related to differences in the drug elimination. While there were statistically significant differences between groups, there is still considerable overlap between the fast, intermediate, and slow populations as shown in fig 1 . This indicates that there are other important determinants of elimination, such as age, nutritional status, disease burden, and the interactions with other drugs. There may also be random individual variation not explained by such factors. Thus, the genotype may not necessarily always be a good predictor of the phenotype. As fig 1 indicates, the combined curve showing the AUC measures for children in all three genetic groups is biphasic rather than triphasic. The FF and FS genotype have a similar phenotype, while those with the SS genotype have greater AUC values. The combined data reveals a bimodal distribution, with considerable overlap between the two groups. Through the use of modern technology, particularly microarray technology, it should be possible to develop a rapid test to assist physicians in the management of a child (or adult) with tuberculosis. ${ }^{15}$ The question that remains is, would such a step be a useful addition to the management of tuberculosis?

In children, metabolic rate is determined mainly by size. Traditionally this has been interpreted as a function of liver size such that younger children have more liver per body weight. Often allometric scaling is used to define the relation between size and metabolic processes. ${ }^{16}$ This relation states that the metabolic rate of an organism is proportional to (weight) ) $^{3 / 4}$ :

\section{Drug elimination $\propto \mathrm{Wt}^{3 / 4}$}

Several pharmacokinetic studies have shown that this relation holds for drug metabolism in children such that dose scales to (body weight) ${ }^{3 / 4}$ better than body weight alone. ${ }^{17} 18$ This may also explain why body surface area also scales well for dose as the commonly used equation approximates the allometric model.

Tuberculosis, like most infectious diseases, is predominantly a disease affecting developing countries. The World Health Organisation is the authority on which most developing countries rely for guidance on the use of drugs and vaccines. For good reasons, WHO always endeavours to produce recommendations that are practical and simple to 


\section{The procrustean approach}

Procrustes was the ancient champion of enforced conformity. He was a highwayman in Greek antiquity. He would measure each of his victims on his standard bed. If they were too short he would stretch them, while if they were too tall, he would cut off their legs; thus one size (bed) fits all.

apply in the field, thus the Procrustean approach. For many drugs this can be achieved and despite the competing influences that affect the dose-effect equation, most drugs can be adequately administered using a one size fits all approach for adults and a simple age or weight related schedule for children. Only a few drugs require dose adjustment based on therapeutic drug monitoring as, for most drugs, the therapeutic window is wide enough to ensure that the minimum effective dose is well below the toxic dose. ${ }^{19}$ The need for monitoring drug levels would make the use of a drug virtually impossible to implement in the context of the developing world, due to the costs involved and the complexity of the test and its interpretation. INH appears to be in an intermediate group between these two extremes. The currently recommended dose in children of $10 \mathrm{mg} / \mathrm{kg}$ treats the vast majority of children adequately without an unacceptably high rate of side effects. However, there are some dose dependent adverse effects, and identifying a group of children likely to have higher drug levels, and therefore at higher risk of side effects may improve treatment adherence and safety, as this group would be adequately treated with a lower dose. Identification of this group may also enable the use of a larger standard dose in children. Thus, knowledge of the patient's metaboliser status could further optimise INH therapy. ${ }^{20}$ While the technology to perform this is presently available, it is currently too expensive and inconvenient. ${ }^{21} 22$ It is conceivable that in the not too distant future polymorphisms at a single locus could be defined by a simple bedside

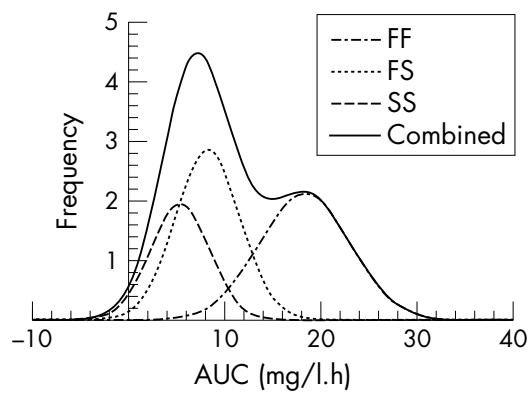

Figure 1 Distribution of AUC values based on genotype. This graph is based on the isoniazid AUC distribution data from Schaaf et al. test on blood, urine, or cheek swab. To know whether this is a concept worth pursuing we need to know much more about the dose related toxicity of isoniazid among malnourished children living in rural areas of the developing world, at the current dose, and possibly at a higher dose. If there is significant dose related toxicity, there would be a strong argument to develop this as a bedside test for the developing world to improve the safety and acceptability of tuberculosis treatment. Isoniazid may be the ideal candidate drug to investigate the impact of the widespread application of a simple pharmacogenetic test on clinical outcomes in a whole world environment.

WHO treatment guidelines reach into all corners of the world in the form of an army of health workers and countless guidelines and training materials developed at country level. Any change in the guidelines is difficult and expensive and creates the risk of confusion in the field. Although Schaff et al do not specifically recommend a change in the guidelines, the fact that almost half the children in their fast acetylator group do not achieve the recommended levels at two and three hours raises the possibility that the dose for children under 5 years of age should be raised. WHO's Tuberculosis Control Programme has paid little attention to the problem of childhood tuberculosis, despite growing evidence that the disease is underdiagnosed in children. The paper by Schaff et al should prompt WHO to undertake a careful review of isoniazid dosage in children. Perhaps it is time for a randomised controlled trial comparing the current dosage with a higher dose in children, examining toxicity, tolerability, and perhaps effectiveness. Based on the results of such a trial, consideration should then be given to the need for a rapid test to identify the group of slow acetylators who may be at higher risk of toxicity. Such developments could lead to fewer side effects, better adherence to therapy, and possibly more effective therapy.

\section{ACKNOWLEDGEMENTS}

The authors would like to thank Mr Philip Greenwood for help with the graphics and Dr Allen Yung for comments on the manuscript.

doi: 10.1136/adc.2004.063610
Arch Dis Child 2005;90:551-553.

\section{Authors' affiliations}

N Cranswick, Australian Paediatric Pharmacology Research Unit, Royal Children's Hospital and Murdoch Children's Research Institute, University of Melbourne, Australia K Mulholland, Department of Infectious and Tropical Diseases, London School of Hygiene and Tropical Medicine, Keppel Street, London, UK

Correspondence to: Prof. K Mulholland, Infectious Disease Epidemiology Unit, Department of Infectious and Tropical Diseases, London School of Hygiene and Tropical Medicine (University of London), Keppel Street, London WCIE 7HT, UK; kim.mulholland@ wch.org.au

Competing interests: none declared

\section{REFERENCES}

1 Dye C, Scheele S, et al. Consensus statement. Global burden of tuberculosis: estimated incidence, prevalence, and mortality by country WHO Global Surveillance and Monitoring Project. JAMA 1999:282:677-86.

2 Schaaf HS, Parkin DP, Seifart HI, et al. Isoniazid pharmacokinetics in children treated for respiratory tuberculosis. Arch Dis Child 2005;90:614-18.

3 Reed MD, Besunder JB. Developmental pharmacology: ontogenic basis of drug disposition. Pediatr Clin North Am 1989;36:1053-74

4 Palanduz A, Gultekin D, Erdem E, et al. Low level of compliance with tuberculosis treatment in children: monitoring by urine tests. Ann Trop Paediatr 2003;23:47-50.

5 Bass JB Jr, Farer LS, Hopewell PC, et al. Treatment of tuberculosis and tuberculosis infection in adults and children. American Thoracic Society and The Centers for Disease Control and Prevention. Am J Respir Crit Care Med 1994; 149:1359-74.

6 Basso LA, Zheng R, Musser JM, et al. Mechanisms of isoniazid resistance in Mycobacterium tuberculosis: enzymatic characterization of enoyl reductase mutants identified in isoniazidresistant clinical isolates. $J$ Infect Dis 1998;178:769-75.

7 Nolan CM, Goldberg SV, Buskin SE, et al. Hepatotoxicity associated with isoniazid preventive therapy: a 7-year survey from a public health tuberculosis clinic. JAMA 1999;281:1014-18.

8 Schaberg T, Rebhan K, Lode H. Risk factors for side-effects of isoniazid, rifampin and pyrazinamide in patients hospitalized for pulmonary tuberculosis. Eur Respir $J$ 1996:9:2026-30.

9 Nakajo MM, Rao M, Steiner P. Incidence of hepatotoxicity in children receiving isoniazid chemoprophylaxis. Pediatr Infect Dis J 1989:8:649-50.

10 Pellock JM, Howell J, Kendig EL Jr, et al. Pyridoxine deficiency in children treated with isoniazid. Chest 1985;87:658-61.

11 American Academy of Pediatrics Committee on Infectious Diseases. Chemotherapy for tuberculosis in infants and children. Pediatrics 1992;89:161-5.

12 Steimer W, Potter JM. Pharmacogenetic screening and therapeutic drugs. Clin Chim Acta 2002;315:137-55.

13 Rey E, Gendrel D, Treluyer JM, et al. Isoniazid pharmacokinetics in children according to acetylator phenotype. Fundam Clin Pharmacol 2001; 15:355-9.

14 Seifart HI, Parkin DP, Botha FJ, et al. Population screening for isoniazid acetylator phenotype. Pharmacoepidemiol Drug Safety 2001;10:127-34.

15 Gerhold DL, Jensen RV, Gullans SR. Better therapeutics through microarrays. Nat Genet 2002;32(suppl):547-51. 
16 West GB, Woodruff WH, Brown JH. Allometric scaling of metabolic rate from molecules and mitochondria to cells and mammals. Proc Natl Acad Sci U S A 2002;99(suppl 1):2473-8.

17 Anderson BJ, Woollard GA, Holford NH. A model for size and age changes in the pharmacokinetics of paracetamol in neonates, infants and children.
Br J Clin Pharmacol 2000;50 125-34.

18 Anderson BJ, Holford NH, Woollard JA Aspects of theophylline clearance in children. Anaesth Intensive Care 1997;25:497-501.

19 Boreus LO. The role of therapeutic drug monitoring in children. Clin Pharmacokinet 1989;17(suppl 1):4-12.
20 Rey E, Pons G, Cremier O, et al. Isoniazid dose adjustment in a pediatric population. Ther Drug Monit 1998;20:50-5.

21 Veenstra DL, Higashi MK, Phillips KA, et al. Assessing the cost-effectiveness of pharmacogenomics. AAPS Pharm Sci 2000;2:e29.

22 Danzon $\mathbf{P}$, Towse A. The economics of gene therapy and of pharmacogenetics. Value in Health 2002;5:5-13.
Immunisation

\section{Childhood immunisations and the development of atopic disease}

\section{Grüber}

\section{Commentary on the paper by Bremner et al (see page 567)}

$\mathrm{P}$ arents of children at heightened risk for atopy are frequently concerned about early immunisations. Apart from concerns about rare allergic reactions to the vaccine antigens or contaminants themselves (reviewed in Grüber and colleagues ${ }^{1}$ ), there exists a fear that immunisations may promote the development of atopic disease, leading to delayed or incomplete vaccination of these children. Some reports about an association of immunisation and atopic disease have fuelled this fear.

Moreover, the rising prevalence of allergic diseases in many industrialised countries has been associated with improvement in hygiene standards. It is thought that a lack of microbial stimuli delays the maturation from the fetal Th2 skewed immune system towards the more Thl balanced immune system of the school child, and thus renders children more susceptible to Th2 dependent allergic disease. In this context, early childhood vaccinations have been viewed as a promoter of atopy development, either directly by the administration of agents which induce a Th2-type immune response or indirectly by the prevention of infections which otherwise would induce a preferential Thl-type immune response, and would thus skew the cytokine balance away from atopy. ${ }^{2}$

What is the currently available evidence for an atopy promoting effect of early childhood immunisations? An IgE response to vaccine antigens is commonly detectable in the sera of vaccinated children. About $50 \%$ of infants have detectable IgE against diphtheria/ tetanus after primary vaccination, ${ }^{3}$ and after booster vaccination later in life more than $90 \%$ of vaccinees have detectable IgE against the vaccine antigens. ${ }^{4}$ The IgE response to vaccine antigens seems to be more pronounced among atopic individuals, ${ }^{35}$ but the correlation of $\operatorname{IgE}$ and protective IgG against the vaccine antigens is poor. ${ }^{67}$ $\operatorname{IgE}$ formation against vaccine antigens should thus be regarded as a regular component of the immune response, although exaggerated in atopics. It should be noted that an IgE response to vaccine antigens is not predictive of allergic side effects to the vaccine.

By contrast, there is no convincing evidence that $\operatorname{IgE}$ formation against nutritive or inhalant allergens is enhanced by routine vaccinations. Longitudinal data from infants in a Swedish controlled pertussis vaccine trial and from a German observational birth cohort show no increased sensitisation rate following pertussis vaccination. ${ }^{68}$ In fact, better general vaccination coverage in the latter cohort was dose dependently associated with a transient reduction of the risk for allergic sensitisation to allergens up to age 5 years. ${ }^{9}$ Two cross-sectional studies, however, suggested an association of vaccination and allergic sensitisation against environmental allergens by deprivation of natural infections. Among pupils from a Swedish anthroposophic school, likely to follow a more traditional lifestyle, including diet and healthcare, measles/mumps/rubella vaccination (MMR) was less common than in regular schools ( $18 \% v 93 \%)$, as was allergic sensitisation $(24 \% \vee v 34 \%$, respectively), but a history of measles was more common $(61 \% \vee 1 \%$, respectively). ${ }^{10}$ In Guinea-Bissau, surviving measles cases from a devastating measles epidemic were less frequently sensitised to environmental allergens than children who were vaccinated against measles. ${ }^{11}$ It is unclear, however, to what extent a selection bias due to a loss of children with a less efficient Thl immune response to the measles infection has flawed the results.

Does routine immunisation promote the development of allergic disease? In many cases, atopic dermatitis is the earliest clinical manifestation of the "atopic march". Parents frequently report an onset of atopic dermatitis after primary immunisation, but this is generally what would be expected with regard to the peak incidence of the disease. A recent longitudinal survey with 9744 children followed up from birth to 3-15 years reported an almost twofold incidence ratio of atopic dermatitis among measles, mumps, and rubella vaccinated children versus nonvaccinated children; the incidence ratio for measles infected children, however, was similar. ${ }^{12}$ For pertussis vaccination, no effect was seen in the Swedish trial. ${ }^{13}$ In the German cohort, measles/mumps vaccinated children with a family history of atopic disease were less likely to experience atopic dermatitis up to age 5 years than non-vaccinated children (OR $0.50,95 \%$ CI 0.29 to 0.86 ), and a dose dependent inverse association of atopic dermatitis and better vaccination coverage in general was noted. ${ }^{9}$ A large international cross-sectional study involving more than 100000 children (ISAAC) showed a weak negative association of atopic dermatitis and better diphtheria-tetanus-pertussis or measles vaccination coverage. ${ }^{14}$

Some cross-sectional studies suggested an association of asthma symptoms and vaccination. In a retrospective, non-randomised study, $11 \%$ of 243 children vaccinated against diphtheria, tetanus, and pertussis but only $2 \%$ of 203 non-vaccinated children developed subsequent asthma. ${ }^{15}$ In New Zealand, none of 23 children without documented vaccination against diphtheria, tetanus, pertussis, and polio developed asthma, but $23 \%$ of 1242 vaccinated children had asthma episodes. ${ }^{16}$ The Swedish pertussis trial showed no association of pertussis vaccination and asthma symptoms. ${ }^{13}$ In ISAAC, there was a weak negative association of asthma symptoms with local birth-year immunisation rates for DTP and measles, ${ }^{14}$ and in the German birth 
cohort study, again a dose dependent reduction of asthma with better vaccination coverage was seen. ${ }^{9}$

Allergic rhinitis is a relatively late event of the "atopic march". In ISAAC, a negative association of allergic rhinitis and DTP or measles vaccination was found among adolescents. ${ }^{14}$ In the pertussis trial, no association was found except a higher prevalence of allergic rhinitis at 7 years for children initially immunised with the two component pertussis vaccine and who received a booster dose with an acellular vaccine compared with those who received no booster vaccination (relative risk 3.6; $95 \%$ CI 1.1 to 12.0$).{ }^{13}$ In this issue, Bremner et al show no risk reduction of hay fever among children who received DTP and MMR vaccination on time; among those with delayed completion of these vaccinations, however, a reduced risk for hay fever is reported. ${ }^{17}$ The authors hypothesise that intercurrent infections account for the delay in vaccination and for the hay fever risk reduction.

By contrast to allegedly Th2 promoting vaccines, BCG has gained recent interest as an antagonist of exaggerated effector T-cell immune responses. Numerous experimental studies show the capacity of mycobacterial preparations to down-regulate allergic sensitisation and allergen induced airway hyperreactivity.$^{18-20}$ Following the observation that tuberculin reactions among BCG vaccinated children from a region with a high mycobacterial burden was inversely associated with total IgE, allergic sensitisation, and allergic symptoms, ${ }^{21}$ a large series of epidemiological studies investigating mainly children from low tuberculosis incidence countries have mostly failed to confirm this inverse association (reviewed in Grüber and $\mathrm{Paul}^{22}$ ). Accordingly, Bremner et al report in this issue no protective effect of BCG vaccination against hay fever in British children. ${ }^{17}$ Results of attempts to employ mycobacterial vaccines as a therapeutic agent in allergic disease have been inconsistent so far. ${ }^{23-27}$ Prospective prevention trials are lacking. Neonatal BCG vaccination has been abandoned in many countries with a low tuberculosis incidence because of its limited efficacy against tuberculous infection and potentially severe side effects. Reintroduction of BCG vaccination as an atopy preventing measure is clearly not justified.

Other bacterial antigens such as cellular pertussis seem to down-regulate IgE to co-administered antigens. ${ }^{6}$ In an experimental model, pertussis also down-regulates hyperresponsiveness to a model allergen (personal observation). Theoretically, it seems to be possible

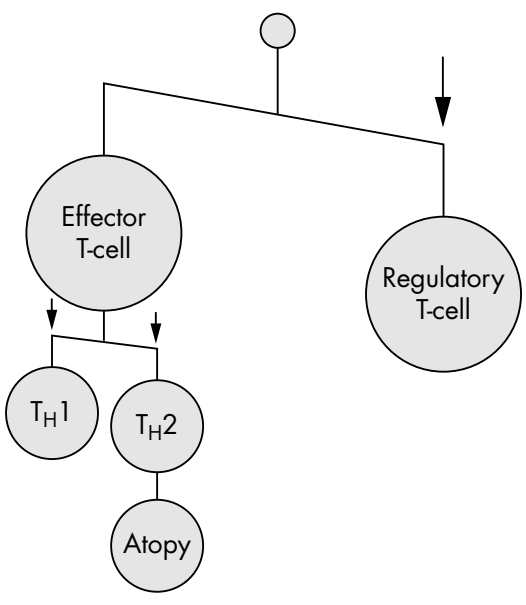

Figure 1 Hypothetical model illustrating putative effects of common childhood vaccines (arrows) on the immune balance and atopy. Th, T-helper cell.

to simultaneously induce immunity against infectious agents and tolerance against allergens. ${ }^{28}$ In the light of recent advances in the understanding of relatively harmless infectious agents as adjuvants for regulatory $\mathrm{T}$-cell induction, ${ }^{29}$ vaccines may be considered for atopy prevention as a vehicle with an extensive safety record in children.

How can we understand the findings regarding early immunisation and atopy with regard to the hygiene hypothesis? Routine immunisations effectively protect our children from potentially harmful disease which thus leads to a reduction in microbial stimulation. Considering experimental data, it seems biologically plausible that vaccines may serve as a surrogate stimulus for the developing immune system. A possible atopy inhibiting effect by better vaccination coverage as suggested by some epidemiological data might be more relevant to the development of atopic disease than vaccine induced Th2-type phenomena.

Parents of children about to be vaccinated should be reassured that common childhood vaccines are unlikely to promote atopic disease, and be informed that possible future development of atopic symptoms is most likely not causally related to vaccination but a coincidence. It remains to be elucidated whether vaccines specifically designed to down-regulate Th-2 type immunity are safe and effective in preventing the development of atopic disease. In the meantime, effective protection against potentially life threatening or disabling infectious diseases should be offered to every child-atopic or not.

Arch Dis Child 2005;90:553-555.

doi: 10.1136/adc.2004.061960
Correspondence to: $\operatorname{Dr} C$ Grüber, Department of Paediatric Pneumology and Immunology, Charité-Universitary Medicine Berlin, A Joint Institution of Free University and Humboldt University, Augustenburger Platz 1, D-13353 Berlin, Germany; christoph.grueber@ charite.de

Competing interests: none declared

\section{REFERENCES}

1 Grüber C, Nilsson L, Björkstén B. Do early childhood immunizations influence the development of atopy and do they cause allergic reactions? Pediatr Allergy Immunol 2001;12:296-311.

2 Rook GA, Stanford JL. Give us this day our daily germs. Immunol Today 1998;19:1 13-16.

3 Dannemann A, van Ree R, Kulig M, et al. Specific $\lg E$ and $\lg G 4$ immune responses to tetanus and diphtheria toxoid in atopic and nonatopic children during the first two years of life. Int Arch Allergy Immunol 1996;11 1:262-7.

4 Mark A, Biörkstén B, Granström M. Immunoglobulin $E$ responses to diphtheria and tetanus toxoids after booster with aluminiumadsorbed and fluid DT-vaccines. Vaccine 1995; 13:669-73.

5 Nilsson L, Grüber C, Granström M, et al. Pertussis $\lg \mathrm{E}$ and atopic disease. Allergy 1998;53:1195-201.

6 Grüber C, Lau S, Sommerfeld C, et al. Downregulation of $\lg E$ and $\lg G 4$ antibodies to tetanus toxoid and diphtheria toxoid by covaccination with cellular Bordetella pertussis vaccine. J Immunol 2001;167:2411-17.

7 Holt PG, Rudin A, Macaubas C, et al. Development of immunologic memory against tetanus toxoid and pertactin antigens from the diphtheria-tetanus-pertussis vaccine in atopic versus nonatopic children. J Allergy Clin Immunol 2000;105: $1117-22$.

8 Nilsson L, Kjellman NI, Biörkstén B. A randomized controlled trial of the effect of pertussis vaccines on atopic disease. Arch Pediatr Adolesc Med 1998;152:734-8.

9 Grüber C, Illi S, Lau S, et al. Transient suppression of atopy in early childhood is associated with high vaccination coverage. Pediatrics 2003; 111:e282-8

10 Alm JS, Swartz J, Lilja G, et al. Atopy in children of families with an anthroposophic lifestyle. Lancet 1999:353:1485-8.

11 Shaheen SO, Aaby P, Hall AJ, et al. Measles and atopy in Guinea-Bissau. Lancet 1996;347:1792-6.

12 Olesen AB, Juul S, Thestrup-Pedersen K. Atopic dermatitis is increased following vaccination for measles, mumps and rubella or measles infection. Acta Derm Venereol 2003;83:445-50

13 Nilsson L, Kjellman NI, Biörkstén B. Allergic disease at the age of 7 years after pertussis disease at the age of 7 years after pertussis
vaccination in infancy: results from the follow-up of a randomized controlled trial of 3 vaccines. Arch Pediatr Adolesc Med 2003;157:1 184-9.

14 Anderson HR, Poloniecki JD, Strachan DP, et al. Immunization and symptoms of atopic disease in children: results from the International Study of Asthma and Allergies in Childhood. Am J Public Health 2001;91:1126-9.

15 Odent MR, Culpin EE, Kimmel T. Pertussis vaccination and asthma: is there a link? JAMA 1994;272:592-3.

16 Kemp T, Pearce N, Fitzharris $P$, et al. Is infant immunization a risk factor for childhood asthma or allergy? Epidemiology 1997;8:678-80.

17 Bremner SA, Carey IM, DeWilde S, et al. Timing of routine immunisations and subsequent hay fever risk. Arch Dis Child 2005:90:567-73.

18 Erb KJ, Holloway JW, Sobeck A, et al. Infection of mice with Mycobacterium bovis - Bacillus Calmette-Guerin (BCG) suppresses allergeninduced airway eosinophilia. J Exp Med 1998;187:561-9.

19 Herz U, Gerhold K, Grüber C, et al. BCG infection suppresses allergic sensitization and development of increased airway reactivity in an animal model. J Allergy Clin Immunol 1998;102:867-74. 
20 Wang CC, Rook GA. Inhibition of an established allergic response to ovalbumin in BALB/c mice by killed Mycobacterium vaccae. Immunology 1998;93:307-13.

21 Shirakawa T, Enomoto T, Shimazu S, et al. The inverse association between tuberculin responses and atopic disorder. Science 1997;275:77-9.

22 Grüber C, Paul KP. Tuberculin reactivity and allergy. Allergy 2002;57:277-80.

23 Arkwright PD, David TJ. Intradermal administration of a killed Mycobacterium vaccae suspension (SRL 172) is associated with improvement in atopic dermatitis in children with moderate-to-severe disease. J Allergy Clin Immunol 2001;107:531-4.

24 Arkwright PD, David TJ. Effect of Mycobacterium vaccae on atopic dermatitis in children of different ages. Br J Dermatol 2003;149:1029-34.

25 Shirtcliffe PM, Easthope SE, Cheng S, et al. The effect of delipidated deglycolipidated (DDMV) and heat-killed Mycobacterium vaccae in asthma. Am J Respir Crit Care Med 2001:163:1410-14.

26 Choi IS, Koh YI. Therapeutic effects of BCG vaccination in adult asthmatic patients:

\section{IgE mediated food allergy: when is food challenge needed?}

\section{P W Ewan, A T Clark}

\section{Commentary on the paper by Roberts (see page 564)}

$\mathrm{R}$ oberts' title is apt, but perhaps it should read challenging times for food allergy (or even for paediatricians). ${ }^{1}$ We are faced with an epidemic of allergy. The prevalence is rising, and recent data show over $30 \%$ of the population and $40 \%$ of children are affected. ${ }^{2}$ Food allergy is a particularand seemingly increasing-problem in children, yet there is a dearth of trained allergists in the UK. ${ }^{34}$

Children have always suffered from egg or cows' milk allergy, and it is well known that these resolve in the majority, often by 5 years of age. ${ }^{56}$ But new IgE mediated food allergies are appearing. The rise in peanut allergy is well documented. This was rare until the early 1990s, the first "big" series being published in 1996. ${ }^{7}$ The prevalence in children rose threefold over 4-6 years from 1 in $200^{8}$ to 1 in $70,{ }^{9}$ and allergy to any nut now occurs in 1 in 50 (Dr Gideon Lack, ALSPAC data, personal communication).

We are faced with other new food allergies: allergy to fruits and vegetables, as part of the oral allergy syndrome (OAS) is now the "new" epidemic. These patients have rhinoconjunctivitis due to pollen allergy (especially birch), and through cross reacting proteins also react to fruits and vegetables. Children are also presenting with allergy to kiwi, sesame, and a range of other foods, distinct from OAS, but at lower rates. ${ }^{10}$

Good management of any disease requires knowledge of the natural history. While this is well known for egg and milk allergy, it is not for the newer disorders, for example peanut, kiwi, and sesame allergy.

\section{DIAGNOSIS}

Diagnosis can usually be made from the history backed up by evidence of specific IgE antibody. It therefore seems surprising that challenge is often suggested to confirm food allergy. ${ }^{1}$ Roberts rightly emphasises the importance of history. This is key to diagnosis, and is easier to interpret in immediate onset food induced reactions. The time interval between ingestion and onset is short, symptoms are typical, and in severe reactions progress is usually rapid and respiratory symptoms dominate.

\section{SKIN PRICK TESTS}

Skin prick tests are immensely helpful but interpretation is vital. A positive skin prick test supports the diagnosis suspected from the history. A negative refutes this. Of course there are always caveats; interpretation should be in light of the history as emphasised by Roberts ${ }^{1}$ and valid allergen extracts should be used. While commercial extracts are excellent for many food allergens, they are of no value for certain foods (for example, prick-prick tests should be used for fruits). Technique of skin testing, including attention to negative controls, is also important, and this is difficult to achieve unless done regularly.

An important distinction is the difference between sensitisation and clinical allergy. Sensitisation is the presence of specific IgE; this may occur without clinical expression of allergy but is a necessary precursor. A positive test shows the presence of specific IgE. The "false positive" Roberts refers to is not really a false positive-specific IgE is there. It is the consequence that varies: randomized, controlled trial. Ann Allergy Asthma Immunol 2002:88:584-91.

27 Choi IS, Koh YI. Effects of BCG revaccination on asthma. Allergy 2003;58:1114-16.

28 Holt PG, Sly PD, Martinez FD, et al. Drug development strategies for asthma: in search of a new paradigm. Nat Immunol 2004;5:695-8.

29 Rook GA, Adams V, Hunt J, et al. Mycobacteria and other environmental organisms as immunomodulators for immunoregulatory disorders. Springer Semin Immunopathol 2004;25:237-55. allergy or no allergy. Failure to understand this is why allergy testing is sometimes viewed with scepticism.

Using peanut allergy as an example, skin tests of $8 \mathrm{~mm}$ or greater, are almost always associated with allergy. ${ }^{11}{ }^{12}$ If the skin test is in the $3-7 \mathrm{~mm}$ range, approximately half will be allergic and half tolerant, so this is a grey area where interpretation is important. Thus a skin test in this range with a typical history confirms allergy. Similarly cut-offs predictive of allergy have been determined for other foods: for egg this is $7 \mathrm{~mm}$ and for cows' milk $8 \mathrm{~mm} .{ }^{12}$ There are smaller cut-offs in children under 2 years. ${ }^{12}{ }^{13}$

The general conclusion is that history is important and this is best supported by skin prick tests. Skin tests have excellent sensitivity of $>95 \%$, so that a negative result is very helpful, but a low specificity of $50 \%$ (if history is not taken into account). "Blind" testing, where there is no history, is unhelpful.

\section{SERUM SPECIFIC IgE}

The reality is that paediatricians mainly have access to blood tests (serum specific IgE tests, commonly referred to as "RAST" or ImmunoCAP). However they are not as satisfactory as skin tests and do not give identical results. Negative "CAP/RASTs" can be falsely reassuring: for example, in nut allergy this was found in 19\% with a convincing history and positive skin test. ${ }^{11}$ Roberts' criticism of all specific IgE tests seems to be based on serum assays rather than skin tests. Similarly data for egg and cows' milk show a few children have a "100\% diagnostic" skin test level and negative serum specific IgE levels. ${ }^{12}$

\section{WHO NEEDS A CHALLENGE?}

Usually a child with a negative skin test does not need a challenge; those with strong positive skin tests have allergy and in those with intermediate positives the diagnosis needs to be informed by the history. The history is usually sufficient in the case of acute reactions. Graham Roberts and Gideon Lack pointed out the power of combining history (pre-test probability) with skin tests (likelihood ratio) to give a post-test probability of food allergy. ${ }^{14}$ There is no doubt that 
experience, particularly of large numbers of the same type of case, is important.

The approach is different with chronic symptoms. With a positive skin test and no history of immediate reactions to that food, for example, a child with eczema or asthma, the correct approach would be a trial of dietary exclusion then reintroduction, at home with a symptom diary. Another scenario is a child with a positive skin test who is eating the food without reaction. Neither of these requires a challenge.

The main clinical indication for challenge is to show resolution of allergy, ${ }^{15}$ for example a child with a clear diagnosis of nut allergy (history supported by positive skin test) who later, after nut avoidance was found to have a negative skin test. However, in practice it would be advisable first to repeat the skin test, after a period of time.

There is no consensus on indications for food challenge, but there is a trend to using this in obvious food allergy. It is time consuming, needs training, and there is an increased risk if patients are poorly selected. Roberts reported a $10.2 \%$ incidence of severe reactions during food challenges but selection criteria were not described. ${ }^{1}$ Morisset et al, in a study designed to identify threshold doses for reactivity, in patients with a convincing history and positive skin test, found serious clinical reactions including hypotension, for egg, milk, peanut, and sesame. ${ }^{16}$ Therefore it seems wise to avoid unnecessary challenges. It is of interest that there are no studies comparing an allergist's diagnosis with challenge. The data showing a discrepancy between perceived allergy/intolerance and challenge, are based on questionnaire or subsets from questionnaires. ${ }^{17}{ }^{18}$

Food challenges are often seen as an easy solution, but this is not the case. They are not straightforward and a number of variables need to be considered. These include factors pertinent to the allergen, for example, dose, matrix (what the food is mixed $\mathrm{in}^{19}$ ), whether cooked or raw; and to the patient, for example, dose $e^{20}$ and masking (which is often difficult to achieve ${ }^{21}$ ), current asthma control, and other active allergies. The starting dose needs to be tailored to the patient, taking account of the severity of the reported reaction(s) and the dose causing this..$^{22}$ As Roberts points out, anxiety may produce subjective or even objective (erythema or vomiting) symptoms. There is no agreed protocol and no two centres do this in the same way. Do you do a double or single blind or open study? It should not be delegated to inexperienced staff, and needs to be done regularly-it is not suitable as a one-off procedure. Assuming patients are appropriately selected, where one is expecting a negative or at worst a mild reaction, an intravenous cannula is not usually required.

\section{WHAT ADVICE SHOULD BE GIVEN AFTER A NEGATIVE CHALLENGE?}

Even this is not straightforward. All one can say is that the child can tolerate that dose, in that form, on that day. The reality is that the majority of patients can then tolerate the food. Rarely will a patient react to open challenge with a food after a negative challenge with $8-10 g^{22}$ the assumption being a larger dose was ingested.

\section{WHAT DOES ALL THIS MEAN?}

The key to dealing with patients with food allergy is having a good clinical knowledge of allergy. This means having experience in allergy history taking, allergens, natural history, and interpretation of allergy tests (whether SPT or RAST) before contemplating food challenge. Food challenge is not for the inexperienced. This leads to bizarre practice with the risk of misdiagnosis. In reality the need for food challenge is reduced by good clinical practice. This is important as food challenges are time consuming and paediatricians are inundated with a heavy allergy case-load and effort should be focused to maximise efficiency. ${ }^{3}$

If the approach suggested above is followed, the need for food challenges is reduced. However, there is much to be discovered and understood and clinical research is needed. Clearly food challenge tests play an important role in research.

There is a huge need for more paediatric allergists and general paediatricians with an interest in allergy. ${ }^{3}$ The problem is broader than food allergy alone because many children have multi-system and often severe allergic disease (including asthma, eczema, and rhinitis). ${ }^{702324}$ Proposals to improve allergy care have been suggested. ${ }^{3424}$

Arch Dis Child 2005;90:555-556.

doi: 10.1136/adc.2004.057372

\section{Authors' affiliations}

P W Ewan, A T Clark, Allergy Dept, Addenbrooke's Hospital, Cambridge University Hospitals NHS Foundation Trust, and University of Cambridge Clinical School, Cambridge, UK

Correspondence to: Dr P W Ewan, Allergy Department, Addenbrooke's Hospital, Hills Road, Cambridge CB2 2QQ, UK. pamela.ewan@addenbrookes.nhs.uk Competing interests: none declared

\section{REFERENCES}

1 Roberts S. Challenging times for food allergy tests. Arch Dis Child 2005;90:564-6.

2 Austin JB, Kaur B, Anderson HR, et al. Hay fever, eczema, and wheeze: a nationwide UK study (ISAAC, international study of asthma and allergies in childhood). Arch Dis Child 1999;81:225.

3 Royal College of Physicians. Allergy: the unmet need. A blueprint for better patient care. A report of the Royal College of Physicians Working Party on the provision of allergy services in the UK. London: Royal College of Physicians, 2003.

4 House of Commons Health Committee. The provision of allergy services. Sixth report of session 2003-04, Volumes I and II. House of Commons, London, 2004. www. publications. parliament.uk/parliamentary_committees/ health_committee $/ \mathrm{cfm} 200304 / \mathrm{cmselect} / 696$ / 696.pdf.

5 Ford RP, Taylor B. Natural history of egg hypersensitivity. Arch Dis Child 1982;57:649.

6 Halken HA, Jacobsen HP, Christiansen AE, et al. Clinical course of cow's milk protein allergy/ intolerance and atopic diseases in childhood. Pediatr Allergy Immunol 2002;13(suppl 15):23-8.

7 Ewan PW. Clinical study of peanut and nut allergy in 62 consecutive patients: new features and associations. BMJ 1996;312:1074-8.

8 Tariq SM, Stevens M, Matthews S, et al. Cohort study of peanut and tree nut sensitisation by age of 4 years. BMJ 1996;313:514-17.

9 Grundy J, Matthews S, Bateman B, et al. Rising prevalence of allergy to peanut in children: Data from sequential cohorts. J Allergy Clin Immunol 2002; 11 10:784-9.

10 Lucas JS, Grimshaw KE, Collins K, et al. Kiwi fruit is a significant allergen and is associated with differing patterns of reactivity in children and adults. Clin Exp Allergy 2004;34:1115-21.

11 Clark AT, Ewan PW. Interpretation of tests for nut allergy in a thousand patients, in relation to allergy or tolerance. Clin Exp Allergy 2003;33:1041.

12 Sporik R, Hill DJ, Hosking CS. Specificity of allergen skin testing in predicting positive open food challenges to milk, egg and peanut in children. Clin Exp Allergy 2000;30:1540-6.

13 Hill DJ, Hosking CS, Reyes-Benito LV. Reducing the need for food allergen challenges in young children: a comparison of in vitro with in vivo tests. Clin Exp Allergy 2001;31:1031-5.

14 Roberts G, Lack G. Food allergy-getting more out of your skin prick tests. Clin Exp Allergy 2000;30:1495-8.

15 Hourihane JO, Roberts SA, Warner JO. Resolution of peanut allergy: a case control study. BMJ 1998;316:1271-5.

16 Morisset M, Moneret-Vautrin DA, Kanny G, et al. Thresholds of clinical reactivity to milk, egg, peanut and sesame in immunoglobulin Edependant allergies: evaluation by double-blind or single-blind placebo-controlled oral challenges. Clin Exp Allergy 2003;33:1046-51.

17 Young E, Stoneham MD, Petruckevitch A, et al. A population study of food intolerance. Lancet 1994;343:1127-30.

18 Hourihane JO, Kilburn SA, Dean TP, et al. Clinical characteristics of peanut allergy. Cin Exp Allergy 1997;27:634-9.

19 Grimshaw KE, King RM, Nordlee JA, et al. Presentation of allergen in different food preparations affects the nature of the allergic reaction-a case series. Clin Exp Allergy 2003;33:1581-5.

20 Hourihane JO, Bedwani SJ, Dean TP, et al. Randomised, double blind, crossover challenge study of allergenicity of peanut oils in subjects allergic to peanuts. BMJ 1997;314:1084-8.

21 Ronteltap A, van Schaik J, Wensing $M$, et al. Sensory testing of recipes masking a peanut or hazelnut for double-blind placebo-controlled food challenges. Allergy 2004;59:457-60.

22 Sicherer SH, Morrow EH, Sampson HA. Doseresponse in double-blind, placebo-controlled oral food challenges in children with atopic dermatitis. J Allergy Clin Immunol 2000;105:582-6.

23 Ewan PW, Clark AT. Long-term prospective observational study of the outcome of a management plan in patients with peanut and nut allergy referred to a regional allergy centre. Lancet 2001;357:111-15.

24 Ewan PW, Clark AT. Efficacy of a management plan based on severity assessment in longitudinal and case controlled studies of 747 children with nut allergy: proposal for good practice. Clin Exp Allergy 2005 (in press) 
Screening

\section{How often should we screen children with Down's syndrome for hypothyroidism?}

\section{G Van Vliet}

\section{Commentary on the paper by Gibson et al (see page 574)}

A side from mental retardation, the prevalence of several health problems is higher in individuals with Down's syndrome than in the general population. Among these problems, hypothyroidism is often noted. At the outset, it is important to distinguish congenital from acquired hypothyroidism. Numerous references continue to state that the prevalence of congenital hypothyroidism is considerably higher in newborns with Down's syndrome than in the general population. ${ }^{2}$ However, the evidence for this is unconvincing: in Quebec, there was no case of Down's syndrome in several hundred children with permanent primary congenital hypothyroidism diagnosed through neonatal screening, suggesting that thyroid dysgenesis (ectopy or agenesis, which account for $85 \%$ of cases of congenital hypothyroidism) is not more frequent in Down's syndrome. ${ }^{3}$ The coexistence of Down's syndrome with severe persistent primary congenital hypothyroidism with a normally located gland of normal or increased size ("dyshormonogenesis") has been reported in a few cases but may represent a chance association. ${ }^{4}$ On the other hand, the distribution of thyrotrophin (TSH) and thyroxine (T4) measured on neonatal blood spots are slightly shifted to the right and left, respectively, in newborns with Down's syndrome compared to the general newborn population. ${ }^{5}$ These shifts are likely present in older individuals with Down's syndrome but this has not been systematically studied. The bioactivity of thyrotrophin being normal, a state of mild thyroidal resistance to thyrotrophin was proposed; ${ }^{6}$ however, the genes coding for TSH receptor and Gs-alpha, two proteins known to be involved in mild TSH resistance, are normal in patients with Down's syndrome. ${ }^{7}$ Furthermore, it is questionable to label as hypothyroidism this shift of thyroid function values of the whole population with Down's syndrome, especially in view of the fact that they do not seem to be associated with abnormal myocardial structure and function. ${ }^{8}$

The higher prevalence of acquired hypothyroidism, mostly from autoimmune thyroid diseases, in individuals with Down's syndrome is better established. For instance, one of 67 patients younger than 22 years receiving thyroxine in a health region of Scotland had Down's syndrome, clearly higher than expected; ${ }^{9}$ however, the type (congenital or acquired) and the severity of hypothyroidism was not known in all these patients. The study by Gibson et al in this issue addresses the question of the frequency of screening that is necessary to detect hypothyroidism at a preclinical stage in young patients with Down's syndrome. ${ }^{10}$ The authors measured TSH and T4 levels and the thyroid antimicrosomal antibody titre in 122 children with Down's syndrome at a median age of 9.8 years (range 6-14). One hundred and three subjects were sampled again at a median age of 14.4 years (range 10-20). At first sampling, the commonest abnormality was isolated hyperthyrotropinaemia, which was observed in 20 patients; however, only one of those was found to be hypothyroid at second testing, thyrotrophin levels had become normal in 14 and isolated hyperthyrotropinaemia persisted in five. Hypothyroidism was also present at second sampling in two patients who were euthyroid at first sampling. Isolated hyperthyrotropinaemia was not associated with reported clinical symptoms. The presence of thyroid autoantibodies on the first test was not significantly associated with hypothyroidism on the second test, although the numbers on which this was evaluated are very small.

The considerations above and the findings of Gibson et al clearly challenge the recommendations of the American Academy of Pediatrics that thyroid function should be evaluated at 6 and 12 months and annually thereafter in all children with Down's syndrome. ${ }^{11}$ One should be aware that US based recommendations are sometimes influenced by considerations that are not of a purely medical nature, such as the need to obtain private insurance coverage for laboratory testing or fear of litigation. Rather than accepting these recommendations at face value, it is appropriate that investigators in every jurisdiction evaluate the evidence supporting a given frequency of screening; the study by Gibson et al is a step in the right direction.

There are, however, several limitations to the study of Gibson et al. Its relatively small sample size has already been mentioned. On the other hand, the two patients who developed hypothyroidism by the time of the second screening did not have growth failure. Given the exquisite sensitivity of postnatal linear growth to hypothyroidism, this is surprising and would suggest that hypothyroidism was of recent onset. In fact, as in all children, deceleration of linear growth associated with weight gain is a sensitive indicator of hypothyroidism, and yearly monitoring of height and weight should allow detection of overt hypothyroidism. ${ }^{12}{ }^{13}$ Lastly, in the era of ultrasensitive TSH assays, the use of TRH stimulation tests to assess subtle primary hypothyroidism is questionable. Indeed, eight of nine patients with a reportedly abnormal TRH test according to Gibson et al had normal TSH three months later.

The principles of population screening $^{14}$ imply that, if an abnormality is identified, there is an effective treatment. While this is clearly the case for congenital hypothyroidism or for overt acquired hypothyroidism, the effectiveness of thyroxine administration to children with Down's syndrome and subtle abnormalities of thyroid function tests has not been rigorously validated. Given the non-specific nature of the symptoms of mild hypothyroidism (constipation, dry skin) and their overlap with manifestations of Down's syndrome itself, only randomised, double blind controlled studies will settle the issue. The only published trial of this nature did not support thyroxine administration, ${ }^{15}$ but was woefully small in scope, with only seven patients studied. Thus, further study is clearly needed on the most sensitive clinical hallmarks of hypothyroidism in children with Down's syndrome, on the minimal biochemical screening frequency, and on the need for thyroxine administration in those with subtle biochemical abnormalities. Meanwhile, clinicians caring for children with Down's syndrome should remain alert to clinical signs of hypothyroidism but do not necessarily need to prescribe yearly blood tests; they should also refrain from treating on the basis of subtle 
biochemical abnormalities alone, which would unnecessarily increase medicalisation of these children who already face a number of genuine developmental and health challenges.

Arch Dis Child 2005;90:557-558.

doi: 10.1136/adc.2004.065607

Correspondence to: $\operatorname{Dr} G$ Van Vliet, Endocrinology Service and Research Center, Sainte-Justine Hospital, Department of Pediatrics, University of Montreal, 3175 SainteCatherine Road, Montreal H3T 1C5, Quebec, Canada; guy.van-vliet@recherche-ste-justine. qc.ca

Competing interests: none declared

\section{REFERENCES}

1 Yang Q, Rasmussen SA, Friedman JM. Mortality associated with Down's syndrome in the USA from 1983 to 1997: a population-based study Lancet 2002;359:1019-25.

2 Refetoff S, Dumont J, Vassart G. Thyroid disorders. In: Scriver CR, Beaudet AL, Sly WS,
Valle D, eds. The metabolic and molecular basis of inherited disease. New York: McGraw-Hill, 2001:4029-76.

3 Devos H, Rodd C, Gagne N, et al. A search for the possible molecular mechanisms of thyroid dysgenesis: sex ratios and associated malformations. J Clin Endocrinol Metab 1999;84:2502-6.

4 Hardy O, Worley G, Lee MM, et al. Hypothyroidism in Down syndrome: screening guidelines and testing methodology. Am J Med Genet 2004:124A:436-7.

5 van Trotsenburg AS, Vulsma T, Van Santen HM, et al. Lower neonatal screening thyroxine concentrations in Down syndrome newborns. J Clin Endocrinol Metab 2003;88:1512-15.

6 Konings $\mathrm{CH}$, van Trotsenburg AS, Ris-Stalpers $C_{\text {, }}$ et al. Plasma thyrotropin bioactivity in Down's syndrome children with subclinical hypothyroidism. Eur J Endocrinol 2001;144:1-4.

7 Tonacchera M, Perri A, De Marco G, et al. TSH receptor and $G$ s(alpha) genetic analysis in children with Down's syndrome and subclinical hypothyroidism. J Endocrinol Invest 2003;26:997-1000.

8 Toscano $\mathrm{E}$, Pacileo $\mathrm{G}$, Limongelli $\mathrm{G}$, et al. Subclinical hypothyroidism and Down's syndrome; studies on myocardial structure and function. Arch Dis Child 2003;88: 1005-8.

9 Hunter I, Greene SA, MacDonald TM, et al. Prevalence and aetiology of hypothyroidism in the young. Arch Dis Child 2000;83:207-10.

10 Gibson PA, Newton RW, Selby K, et al. Longitudinal study of thyroid function in Down's syndrome in the first two decades. Arch Dis Child 2005:90:574-8.

11 American Academy of Pediatrics. Health supervision for children with Down syndrome. Pediatrics 2001;107:442-9.

12 Chemaitilly W, Thalassinos C, Emond S, et al. Metrorrhagia and precocious puberty revealing primary hypothyroidism in a child with Down's syndrome. Arch Dis Child 2003:88:330-1.

13 Van Vliet G. Hypothyroidism in infants, children, an adolescents: acquired hypothyroidism. In: Braverman LE, Utiger RD, eds. The thyroid. Philadelphia: Lippincott, Williams \& Wilkins, 2004

14 Wilson JMG, Jungner G. Principles and practice of screening for disease. Geneva: World Health Organization, 1968.

15 Tirosh E, Taub Y, Scher A, et al. Short-term efficacy of thyroid hormone supplementation for patients with Down syndrome and low-borderline thyroid function. Am J Ment Retard 1989;93:652-6

\section{IMAGES IN PAEDIATRICS}

\section{Stuck long line syndrome}

A 25 weeks gestation male infant, birth weight $918 \mathrm{~g}$ had a percutaneous central venous catheter (PCVC) (Premicath, Vygon) inserted into the left basilic vein on day 6. Necrotising enterocolitis and Staphylococcus epidermidis sepsis complicated the clinical course. On day 36, when full enteral feeds were established, a decision to remove the PCVC was made. It was withdrawn until it became "stuck" with $4 \mathrm{~cm}$ remaining within the vein. Firm traction and limb manipulation was unsuccessful in releasing the PCVC. Ultrasound of the arm demonstrated an echogenic focus adherent to the PCVC and the venous endothelial surface, preventing removal. The PCVC was surgically removed under general anaesthesia. The PCVC was noted to be covered with a tissue sheath adherent to the venous endothelial surface. Histopathology confirmed the sheath to be calcified fibrinous tissue.

It is a natural response of the human body to coat the surface of artificially implanted devices with a proteinaceous film. This "fibrin sheath" can form on the surface of central venous catheters within 24 hours. Fibrin sheaths have been implicated in catheter related sepsis, but this remains unproven. ${ }^{1}$ Reports of the sheath obstructing removal are rare. $^{23}$ Controlled traction was not successful in releasing the catheter. In this case the infant required surgery under general anaesthesia to ensure safe and complete removal.

P M Filan

Department of Neonatology, Royal Children's Hospital, Flemington Road, Parkville, Victoria 3052, Australia; peter.filan@bigpond.com

$M$ Woodward

Department of General Surgery, Royal Children's Hospital

P G Ekert

Department of Neonatology, Royal Children's Hospital

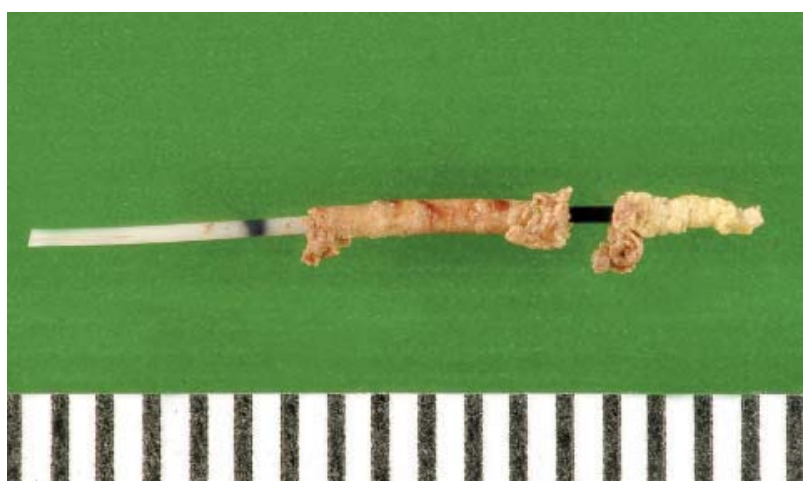

Figure 1 PCVC tip with fibrin sheath (scale in millimetres).

\section{References}

1 Lloyd DA, Shanbhogue LKR, Doherty PJ, et al. Does the fibrin coat around a central venous catheter influence catheter related sepsis? J Pediatr Surg 1993;28:345-9.

$2 \mathrm{Ng}$ PK, Ault MJ, Fishbein MC. The stuck catheter: a case report. Mt Sinai J Med 1997;64:350-2.

3 Gladman G, Sinha S, Sims DG, et al. Staphylococcus epidermidis and retention of neonatal percutaneous central venous catheters. Arch Dis Child 1990;65:234-5. 